\title{
Single machine scheduling with consideration of preventive maintenance and machine health
}

\author{
Kwei-Long Huang ${ }^{1}$, Jakey Blue ${ }^{2}$, Hao-Chen Weng ${ }^{1}$ and Shu-Han Liu ${ }^{1, *}$ \\ ${ }^{1}$ Institute of Industrial Engineering, National Taiwan University, IYC Building, No 1, Roosevelt Road, Sec 4, 10617 Taipei, Taiwan \\ ${ }^{2}$ Manufacturing Sciences and Logistics, École des Mines de Saint-Étienne, Center of Microelectronics in Provence - site Georges \\ Charpak, 880 Route de Mimet, 13541 Gardanne, France
}

\begin{abstract}
Because of Industry 4.0 and Internet of Things, it is easier to collect data from machines through sensors that are embedded inside machines. Once the status change of a machine is detected, production on that machine may need to be adjusted accordingly. In this research, we focus on single machine scheduling with considering the Preventive Maintenance (PM) and machine health index. Machine health index is categorized into three states: good, fair, and breakdown. When the machine moves from one state to another, the processing time of jobs will change as well as the machine failure rate. We develop a model to determine an optimal interval of performing PM and production sequence of jobs. A two-phase heuristic method is proposed to solve a large-size problem. Through different parameter settings, such as the machine failure rate, number of jobs, repair and maintenance cost, we show that the two-phase heuristic can obtain a solution with high quality.
\end{abstract}

\section{Introduction}

As the advance of Internet of Things, more and more production data are collected in a manufacturing factory such that the machine health index can be more truthfully characterized. Well utilizing these data can further enhance and improve production scheduling. For a traditional scheduling problem, the processing time of a job may be assumed independent of the status of machines. That is, a job always requires the same amount of time to be finished on a machine regardless of whether the machine is in a good condition or not. In a practical system, the processing time of a job can vary according to the machine status. When the machine is in different conditions, its capacity or processing speed changes accordingly, e.g., the job processing time becomes longer or shorter. In this study, we consider this characteristic to better reflect the real production environment. In addition, when the machine status changes, actions of maintenance or repair are taken to restore the machine to a better condition. Therefore, we develop a model that determines the production sequence of jobs on one machine with the minimal makespan and the timing of maintenance or repair with the least cost.

Several research topics related to our work such as maintenance, PM, machine health, and hazard rate function are introduced below:

\subsection{Maintenance}

* Corresponding author: Shu-Han Liu r05546023@ntu.edu.tw
Machine will deteriorate or breakdown through planning horizon. In order to avoid machine breakdown, we need to do maintenance effectively. In this research, we adopt so-called perfect repair policy or called "As Good As New (AGAN)" repair [1]. In recent research, Peng and Houtum use joint optimization model to consider maintenance [2]. Manzini, Accorsi, Cennerazzo, Maranesi relaxed the constraints with consideration of cost, reliability and resource respectively to solve the problem [3]. Contrary to them, we aim on the problem that remains all objective and constraints without compromising the soundness and completeness of the problem when solving it.

\subsection{Preventive Maintenance (PM)}

As the information technology advances, it is more and more viable to estimate the machine health [4]. Machine health status affects the machine processing time or workload. When the machine health starts to deteriorate, the machine failure rate may increase and the yield rate will reduce. Through perform the PM, machine health can be significantly improved [5], and the machine failure rate and the repair cost will be efficiently reduced [6, 7]. In this research, we assume that the machine health will become as good as new after performing PM. We also use the objective of minimizing unit time repair cost to determine the optimal interval of PM [8].

\subsection{Machine health}


In the past, machine status was only considered as two states: available and breakdown. Due to the installation of more and more sensors, machine health statuses can be specified more truthfully [9]. Conventionally, machine health status can be measured by hazard rate [10] and reliability [11]. Hazard rate is used to model the transition of machine health status [12] and is also called the failure rate, defined as the instantaneous rate of being irreparable given the machine has functioned for time $t$. In this research, we use hazard function as the transition rate among machine health statuses $[8,13]$.

\section{Problem description}

We try to minimize the total maintenance cost and repair cost through considering the machine health and sequencing the jobs on one machine, and to find the optimal sequence of jobs and the best timing to perform a maintenance.

\subsection{Problem assumption}

- There are three states for machine health: Good (denoted as 2), Fair (1), and Breakdown (0). In the good state, the processing time of each job follows original settings; in the fair state, the processing time of each job will increase; in the breakdown state, the machine cannot process jobs.

- Machine health status will not change until the machine completes a job

- Differ from transition probability of a stochastic problem, we assume the machine health transition (from 2 to 1) follows Hazard Rate Function with Exponential distribution. Machine health transition (from 1 to 0 ) follows Hazard Rate Function with Weibull distribution. The transition is shown in Figure 1.

- When the machine breakdowns, the minimal repair policy is used to fix the machine, that is, the machine is back to Fair state (1).

- PM is assumed to be perfectly performed, which means the machine health status will become as good as new after the maintenance. Also, PM can only be scheduled at the time when the machine is idle.

- Non-Preemptive is assumed, i.e., a job cannot be interrupted in the middle of the processing.

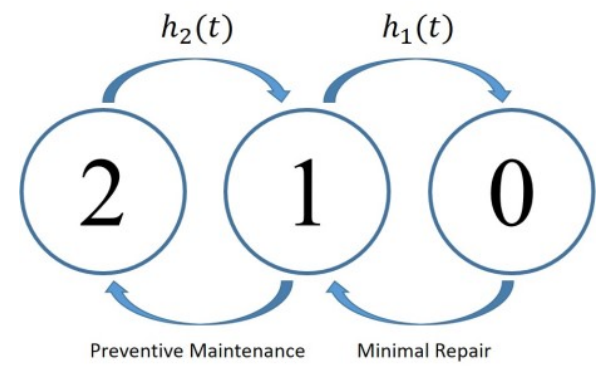

Figure 1 Machine status transition diagram

\subsection{Model}

Tables 1 and 2 summarize the decision variables and parameters used in the model.

Table 1. Decision variables.

\begin{tabular}{|c|c|}
\hline Symbols & Description \\
\hline$y_{i a k}$ & $\begin{array}{l}\text { Job } i \text { is scheduled in ath preventive maintenance } \\
\text { on kth position. }\end{array}$ \\
\hline$x_{i a}$ & $\begin{array}{c}\text { Job } i \text { is scheduled in ath period preventive } \\
\text { maintenance. }\end{array}$ \\
\hline$y_{i k}$ & Job $i$ is scheduled on $k t h$ position. \\
\hline$C_{a}$ & $\begin{array}{c}\text { Repair cost during ath period of preventive } \\
\text { maintenance. }\end{array}$ \\
\hline
\end{tabular}

Table 2. Parameters

\begin{tabular}{|c|c|}
\hline Symbols & Description \\
\hline$p_{i j}$ & $\begin{array}{c}\text { Processing time of job } i \text { when machine is in } \\
\text { state } j .\end{array}$ \\
\hline$C_{P M}$ & Cost of preventive maintenance. \\
\hline$C_{r}$ & Cost of minimal repair. \\
\hline$T_{P M}$ & Time duration of preventive maintenance. \\
\hline$T_{r}$ & Time duration of minimal repair. \\
\hline$N$ & Number of jobs. \\
\hline$J$ & $\begin{array}{c}\text { Upper bound of number of jobs in one } \\
\text { interval of preventive maintenance. }\end{array}$ \\
\hline$h_{2}\left(t_{2}\right)$ & Hazard function (from 2 to 1). \\
\hline$h_{1}\left(t_{1}\right)$ & Hazard function (from 1 to 0). \\
\hline$\alpha, \beta$ & $\begin{array}{r}\text { Weibull distribution, scale parameter } \alpha, \\
\text { shape parameter } \beta\end{array}$ \\
\hline$\lambda$ & Exponential distribution, parameter $\lambda$ \\
\hline$T^{*}$ & Optimal interval of preventive maintenance. \\
\hline
\end{tabular}

Before modeling, we have to find out the optimal interval PM time $T^{*}$. We can see that Hazard function is defined as $\quad h(t)=\frac{f(t)}{1-F(t)} \quad, \quad$ and $\quad U C=$ $\frac{C_{P M}+C_{r}\left[\int_{0}^{T} h_{2}\left(t_{2}\right) \int_{x}^{T} h_{1}\left(t_{1}\right) d t_{1} d t_{2}\right]}{T+T_{P M}+T_{r}\left[\int_{0}^{T} h_{2}\left(t_{2}\right) \int_{x}^{T} h_{1}\left(t_{1}\right) d t_{1} d t_{2}\right]}$, represents machine repair cost and maintenance cost in one unit of time. In order to obtain $T^{*}$ which minimizes unit time repair and maintenance cost, we take first derivative of $\frac{d U C}{d T}=0$ and the repair cost vs time is shown in Figure 2.

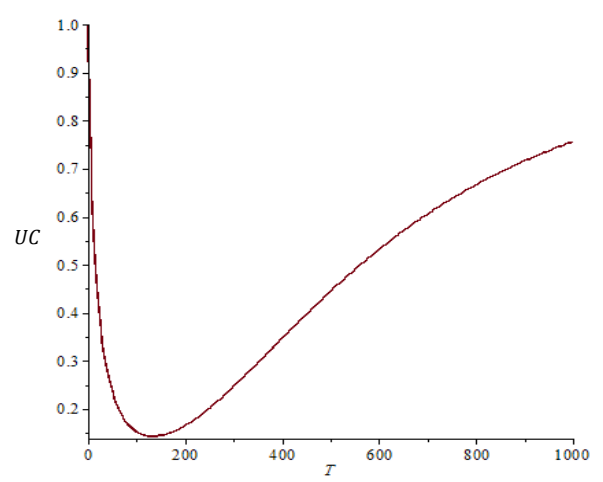

Figure 2 Unit time repair cost 
After finding the PM duration $T^{*}$, we have to define the time duration of state one $\left(T_{1}^{*}\right)$ and two $\left(T_{2}^{*}\right)$ between two maintenances according to the distribution parameter $\lambda$. Then we can use this for the model to find the optimal schedule of the problem.

$$
\operatorname{Min} \sum_{a=1}^{N_{g}} C_{a}+N_{g} \cdot C_{P M}
$$

Subject to:

$$
\begin{gathered}
C_{a}=C_{r} \cdot \sum_{z_{a}=1}^{J}\left\{\left[\int_{\sum_{i=1}^{N} \sum_{k=1}^{Z_{a}-1} p_{i 2} \cdot y_{i a k}}^{N} \sum_{2}^{z_{a}} p_{i 2} \cdot y_{i a k}(x) d x\right] \cdot\right. \\
\left.\left[\int_{\sum_{i=1}^{N} \sum_{k=1}^{\sum_{i=1}} \sum_{k=1}^{Z a} p_{i 2} \cdot y_{i \mathrm{a} k}+\sum_{i=1}^{N} \sum_{k=z_{a}}^{J} p_{i 1} \cdot y_{i \mathrm{a} k}}^{J} \mathrm{~h}_{1}\left(t_{1}\right) d t_{1}\right]\right\}, \forall \mathrm{a} \\
N_{g}=\sum_{a=1}^{N} G_{a} \\
T_{2}^{*}=T^{*} \cdot \frac{\lambda-T^{*}}{\lambda} \\
T_{1}^{*}=T^{*} \cdot \frac{T^{*}}{\lambda} \\
\sum_{i=1}^{N} \sum_{k=1}^{N} p_{i 2} \cdot y_{i a k} \leq T_{2}^{*} \cdot G_{a}, \forall a \\
\sum_{i=1}^{N} \sum_{k=1}^{N}\left(p_{i 1}-p_{i 2}\right) \cdot y_{i a k} \leq T_{1}^{*}, \forall a \\
\sum_{k=1}^{N} \sum_{i=1}^{N} y_{i a k} \leq J, \forall a \\
\sum_{i=1}^{N} y_{i a k} \leq 1, \forall k, \forall a \\
\sum_{a=1}^{N} \sum_{k=1}^{J} y_{i a k}=1, \forall i \\
y_{i a k}, G_{a} \in\{0,1\}
\end{gathered}
$$

Objective (1) is to minimize total expected preventive maintenance cost $\left(N_{g} \cdot C_{P M}\right)$ and repair cost $\left(\sum_{a=1}^{N_{g}} C_{a}\right), N_{g}$ represents the number of preventive maintenances, $C_{P M}$ represents the PM cost for once. Constraint (2) represents the expected repair cost in one interval of PM. Constraint (3) represents the total number of preventive maintenance. Constraint (4) represents time duration of a machine in good state between two PMs. Constraint (5) represents time duration of machine in fair state between two PMs. Constraint (6) means that total the processing time of jobs cannot be longer than the optimal interval of two PMs when the machine is in good state. Constraint (7) means that the total increase of processing time cannot be longer than $T_{1}^{*}$ when the machine is in fair state. Constraint (8) means that total number of jobs in the period of PM cannot exceed $J$. Constraint (9) means that one job can be only processed on one machine. Constraint (10) means that one job can only be processed in one interval between two PMs.

\section{Two-phase Heuristic}

It is time consuming to solve the model when the number of jobs is large, so we develop a two-phase heuristic method to solve the problem efficiently. The model in Section 2.2 is try to schedule all the jobs simultaneously. Because of the complexity, our two-phase heuristic method tried to divide jobs into groups to form a few small problems. In Phase 1, we separate jobs into different intervals of preventive maintenance. In Phase 2, we sequence the jobs in each interval between preventive maintenance. The idea of the proposed algorithm is shown in Figure 3.

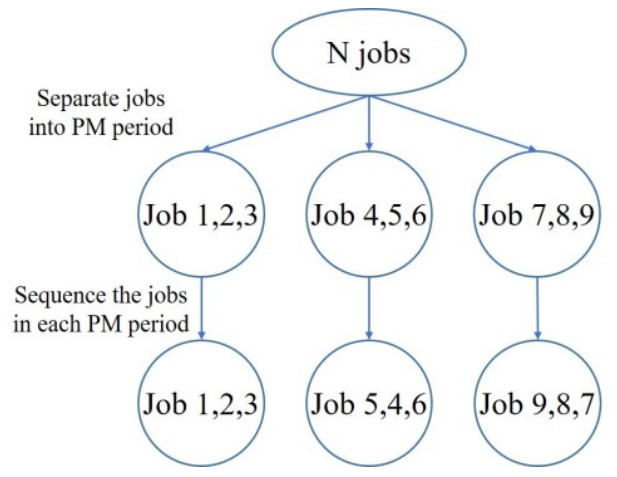

Figure 3 Heuristic method process

- Phase 1: Separating jobs into groups

In this phase, jobs are assigned to different preventive maintenance interval.

$$
\operatorname{Min} N_{g}=\sum_{a=1}^{N} G_{a}
$$

Subject to:

$$
\begin{gathered}
T_{2}^{*}=T^{*} \cdot \frac{\lambda-T^{*}}{\lambda} \\
T_{1}^{*}=T^{*} \cdot \frac{T^{*}}{\lambda} \\
\sum_{i=1}^{N} p_{i 2} \cdot x_{i a} \leq T_{c}^{*} \cdot G_{a}, \forall a \\
\sum_{i=1}^{N} \sum_{k=1}^{N}\left(p_{i 1}-p_{i 2}\right) \cdot y_{i a k} \leq T_{1}^{*}, \forall a \\
\sum_{a=1}^{N} x_{i a}=1, \forall i \\
G_{a}, x_{i a} \in\{0,1\}
\end{gathered}
$$

Objective (12) is to minimize the total number of PMs. Constraint (13) represents time duration of the machine in good state during the interval of preventive maintenance. Constraint (14) represents time duration of the machine in fair state in the interval of preventive maintenance. Constraints (15) means that total processing time of jobs with machine good state cannot be longer than the interval of preventive maintenance. Constraint (16) means that total increase of processing time with machine fair state cannot be longer than $T_{1}^{*}$. Constraint (17) means that each job will be processed in only one period of preventive maintenance. Constraint (18) is a binary constraint.

- Phase 2: Sequence the jobs in a group

In this phase, given jobs assigned in each interval of the $\mathrm{PM}$, the job sequence will be determined to minimize the repair cost:

$$
\begin{gathered}
\operatorname{Min} C_{r} \cdot \sum_{z_{a}=1}^{n}\left\{\left[\int_{\sum_{i=1}^{n} \sum_{k=1}^{z_{a}-1} p_{i 2} \cdot y_{i k}}^{\sum_{k a} z_{a} p_{i 2} \cdot y_{i k}} h_{2}\left(t_{2}\right) d t_{2}\right] \cdot\right. \\
\left.\left[\int_{\sum_{i=1}^{n} \sum_{k=1}^{\sum_{a}} \sum_{k=1}^{z} p_{i 2} \cdot y_{i k} \cdot y_{i k}+\sum_{i=1}^{n} \sum_{k=z_{a}}^{n} p_{i 1} \cdot y_{i k}}^{z_{a}} \mathrm{~h}_{1}\left(t_{1}\right) d t_{1}\right]\right\}
\end{gathered}
$$

Subject to:

$$
\begin{aligned}
& \sum_{i=1}^{n} y_{i k}=1, \quad \forall k \\
& \sum_{k=1}^{n} y_{i k}=1, \quad \forall i
\end{aligned}
$$




$$
y_{i k} \in\{0,1\}
$$

Objective (19) is to minimize repair cost in one interval of preventive maintenance. Constraint (20) means that one position on the machine can only process one job. Constraint (21) means that one job can only be processed on one position on the machine. Constraint (22) is a binary constraint.

\section{Results and Conclusion}

We consider different settings of parameters to examine the effectiveness of the heuristic method.

- Parameter settings

Two types of machines are considered, one with a higher failure rate and the other with a lower failure rate. Machine conditions are shown in Table 3.

Table 3. Machine type condition.

\begin{tabular}{|c|c|c|c|c|c|c|}
\hline $\begin{array}{c}\text { Machine } \\
\text { type }\end{array}$ & $\boldsymbol{C}_{\boldsymbol{P M}}$ & $\boldsymbol{C}_{\boldsymbol{r}}$ & $\boldsymbol{T}_{\boldsymbol{P M}}$ & $\boldsymbol{T}_{\boldsymbol{r}}$ & $\boldsymbol{\lambda}$ & $(\boldsymbol{\alpha}, \boldsymbol{\beta})$ \\
\hline 1 & 20000 & 30000 & 60 & 80 & $1 / 900$ & $(100,2)$ \\
\hline 2 & 20000 & 30000 & 60 & 80 & $1 / 900$ & $(200,2)$ \\
\hline
\end{tabular}

When the machine is in different health status, the processing time of jobs will be different. Processing time becomes longer in fair state. There are 14 jobs and the processing time of each job in states 2 and 1 is shown in Table 4.

Table 4. Processing time of each job.

\begin{tabular}{|c|c|c|c|c|c|c|c|c|}
\hline \multicolumn{2}{|c|}{ Job } & 1 & 2 & 3 & 4 & 5 & 6 & 7 \\
\hline \multirow{2}{*}{\begin{tabular}{c} 
Processing \\
time \\
\cline { 2 - 9 }
\end{tabular}} & $\begin{array}{c}\text { State } \\
2\end{array}$ & 30 & 28 & 36 & 40 & 44 & 48 & 38 \\
\cline { 2 - 9 } & State & 38 & 33 & 45 & 49 & 54 & 55 & 46 \\
\hline \multicolumn{2}{|c|}{ Job } & 8 & 9 & 10 & 11 & 12 & 13 & 14 \\
\hline $\begin{array}{c}\text { Processing } \\
\text { time }\end{array}$ & $\begin{array}{c}\text { State } \\
2\end{array}$ & 26 & 33 & 50 & 39 & 42 & 20 & 32 \\
\cline { 2 - 9 } & 1 & 31 & 42 & 66 & 47 & 52 & 27 & 41 \\
\hline
\end{tabular}

\section{- Parameter settings}

According to the machine health conditions, we find out the optimal interval of preventive maintenance from the model of Section 2.2, $\mathrm{T}^{*}$ of machine type 1 is 162 , and type 2 is 259 .

Based on the results shown in Table 5 and Table 6, we can find out that the proposed two-phase heuristic can efficiently solve the problem, and the quality of solution remains good.

Table 5. Number of jobs in two-phase heuristic (type 1).

\begin{tabular}{|c|c|c|c|c|c|}
\hline \multirow{2}{*}{$\begin{array}{c}\text { of } \\
\text { jobs }\end{array}$} & \multicolumn{2}{|c|}{$\begin{array}{c}\text { Repair and maintenance } \\
\text { cost }\end{array}$} & \multicolumn{2}{|c|}{$\begin{array}{c}\text { Computation time } \\
\text { (sec) }\end{array}$} \\
\cline { 2 - 5 } & $\begin{array}{c}\text { Optimal } \\
\text { model }\end{array}$ & $\begin{array}{c}\text { Two- } \\
\text { phase } \\
\text { heuristic }\end{array}$ & Gap & $\begin{array}{c}\text { Optimal } \\
\text { model }\end{array}$ & $\begin{array}{c}\text { Two- } \\
\text { phase } \\
\text { heuristic }\end{array}$ \\
\hline
\end{tabular}

\begin{tabular}{|c|c|c|c|c|c|}
\hline 8 & 65127 & 65696 & $99 \%$ & 75 & $<1$ \\
\hline 10 & 72248 & 72292 & $99.9 \%$ & 86 & $<1$ \\
\hline 12 & 91838 & 92073 & $99.7 \%$ & 882 & $<1$ \\
\hline 14 & 95938 & 96094 & $99.8 \%$ & 3633 & $<1$ \\
\hline
\end{tabular}

Table 6. Number of jobs in two-phase heuristic (type 2).

\begin{tabular}{|c|c|c|c|c|c|}
\hline \multirow{2}{*}{$\begin{array}{c}\# \\
\text { of } \\
\text { jobs }\end{array}$} & \multicolumn{3}{|c|}{\begin{tabular}{c}
\multicolumn{3}{|c|}{ Repair and maintenance } \\
cost
\end{tabular}} & \multicolumn{2}{c|}{$\begin{array}{c}\text { Computation time } \\
\text { (sec) }\end{array}$} \\
\cline { 2 - 6 } & $\begin{array}{c}\text { Optimal } \\
\text { model }\end{array}$ & $\begin{array}{c}\text { Two- } \\
\text { phase } \\
\text { heuristic }\end{array}$ & Gap & $\begin{array}{c}\text { Optimal } \\
\text { model }\end{array}$ & $\begin{array}{c}\text { Two- } \\
\text { phase } \\
\text { heuristic }\end{array}$ \\
\hline 8 & 43383 & 43649 & $99.3 \%$ & 23 & $<1$ \\
\hline 10 & 63105 & 65605 & $96 \%$ & 67 & $<1$ \\
\hline 12 & 65900 & 66089 & $99.7 \%$ & 376 & $<1$ \\
\hline 14 & 67770 & 68548 & $98.8 \%$ & 1418 & $<1$ \\
\hline
\end{tabular}

In the study, we consider different processing times of a job with respect to different machine states, which is known as the machine health index. An optimal model is constructed to determine the job sequence that minimizes the cost of preventive maintenance and repair. For a large -scale problem, a two-phase heuristic is proposed to find a good solution in a short computational time.

\section{References}

1. Dinh. T. N, Yann. D, Mitra. F, European Journal of Operational Research, 256(2), 439-453. (2017).

2. Peng. H, Houtum. G, European Journal of Operational Research, 253(1), 94-107. (2016).

3. Manzini. R, Accorsi. R, Cennerazzo. T, Maranesi. F, Computers \& Industrial Engineering, 87, 561-568. (2015).

4. Lee. J, Wu. F, Zhao. W, Ghaffari. M, Liao. L, \& Siegel. D, Mechanical Systems and Signal Processing, 42(1), 314-334. (2014).

5. Kazaz. B, \& Sloan. T. W, European Journal of Operational Research, 227(1), 88-100. (2013).

6. Mobley. R.K, An introduction to predictive maintenance: Butterworth-Heinemann. (2002).

7. Ruiz-Castro. J. E., \& Li. Q-L, European Journal of Operational Research, 211(1), 97-111. (2011).

8. Xia. T, Jin. X, Xi. L, \& Ni. J, European Journal of Operational Research, 240(3), 781-790. (2015).

9. Pham. H. T., \& Yang. B-S, Mechanical Systems and Signal Processing, 24(2), 546-558. (2010).

10. Lim. J-H, \& Park. D. H, Asia-Pacific Journal of Operational Research, 24(01), 111-124. (2007).

11. Liao. W, Pan. E, \& Xi. L, Journal of Intelligent Manufacturing, 21(6), 875-884. (2010).

12. Wang. S, \& Liu. M, International Journal of Production Research, 51(3), 847-868. (2013).

13. Yong. J, Condition-based hazard rate estimation and optimal maintenance scheduling for electrical transmission system. (2006). 